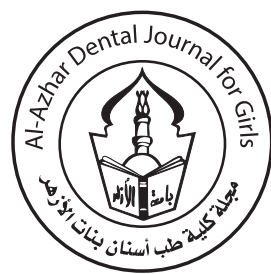

\title{
Effects of Laser Application on Leveling Efficiency Using Different Orthodontic Archwires
}

\author{
Alaa M. El-Hendawey ${ }^{*}$, Samir A. Ibrahim ${ }^{2}$, Ahmed E. Salama ${ }^{3}$, Ossama S. El-Shall ${ }^{4}$.
}

Codex : 38/2004

azhardentj@azhar.edu.eg

http://adjg.journals.ekb.eg

DOI: $10.21608 /$ adjg.2020.14046.1169

Pediatric Dentistry \& Orthodontics ( Pediatric Dentistry, Orthodontics)

\section{KEYWORDS}

Leveling,

Archwires

Laser Therapy.

\begin{abstract}
Purpose: to evaluate the effect of low level laser on leveling and alignment by using two types of orthodontic archwires. Materials and methods: A consecutive sample of 32 patients requiring fixed orthodontic appliances were grouped into four groups: laser group with 0.014 inch copper NiTi wire, laser group with 0.014 inch superelastic NiTi wire, 0.014 inch copper NiTi wire group without laser, 0.014 inch superelastic NiTi wire group without laser. Directly after the first arch wire insertion the investment group received a LLLT dose (laser application group of patients). The LLLT device was adjusted to $635 \mathrm{~nm}$ wavelength and with $2.2 \mathrm{~J} /$ point (energy dosage). There were four points of application regarding each mandibular incisor's root, two of them are buccal and the other two points are palatal. This laser dosage was applied repeatedly on 7, 14 and 28 days for each patient in the laser group. The evaluation of alignment by studying four casts taken along the initial stage of treatment (before treatment T0, Two weeks T1, four weeks T2 and six weeks T3 of treatment). Results: Statistical analysis between the groups revealed that there was no statistically significant difference between the four groups at four different intervals (T0-T1), (T1-T1), (T2-T3) and (T0T3) $(P$-value $=0.813,0.601,0.646,0.340)$ respectively. Conclusion: The two forms of $\mathrm{NiTi}$ wires (superelastic NiTi wire and $\mathrm{Cu}$ NiTi wire) during the alignment process in the initial stage of the treatment were the same regarding the efficiency of alignment, either with or without laser application, and for the acceleration of the tooth movement in orthodontics the application of LLLT wasn't effective during the initial aligning stage of orthodontic treatment either with superelasti NiTi wire or $\mathrm{Cu}$ NiTi wire.
\end{abstract}

- Paper extracted from Master Thesis titled "Effects of Laser Application on Leveling Efficiency Using Different Orthodontic Archwires"

1. Demonstrator of Orthodontics, Faculty of Dental Medicine for Girls, Al-Azhar University, Cairo, Egypt.

2. Professor of Orthodontics, Faculty of Dental Medicine for Girls, Al-Azhar University, Cairo, Egypt.

3. Professor of Orthodontics and Head of Orthodontic, Faculty of Dental Medicine for Girls, Al-Azhar University, Cairo, Egypt.

4. Professor of Oral Medicine, Periodontology, Diagnosis and Radiology, Faculty of Dental medicine for Girls, Al-Azhar University, Cairo, Egypt.

*Corresponding author email: alaa.28sagda@gmail.com 


\section{INTRODUCTION}

Levelling and aligning are terms referring the initial treatment stage of orthodontic therapy. When the incisal edges of anterior teeth go with the buccal cusps of posteriors in the same level horizontally, this is termed levelling. But alignment is the teeth lining in the exact arch form aiming to get normal contact points between the teeth of the same $\operatorname{arch}^{(1,2)}$.

Initiation of orthodontic treatment with "leveling" archwires requires wires with great range to accommodate the usual malalignment of bracket slots in the untreated malocclusion. Low stiffness is advantageous so that the forces can be kept as gentle as possible ${ }^{(3-5)}$. Based on the elastic property ratios of strength, stiffness, and range, two types of wires are suggested, i.e., a multistranded stainless steel wire or a nitinol-type wire ${ }^{(6)}$.

Previous studies have shown that multistranded stainless steel wires provide viable alternative to expensive titanium alloy wires. However, some studies have shown that titanium alloys are superior wires during aligning and leveling ${ }^{(7,8)}$.

Arch wires of nickel titanium are usually differentiated into three types which named as conventional, thermoactivated and superelastic nickel titanium arch wires ${ }^{(9)}$.

This last type of wires performed the same amount of force, regardless the activation degree, this is why it is superelastic ${ }^{(10)}$.

Heat-activated NiTi alloys emerged, for commercial purposes, in the 1990's. The most recent improvement is copper NiTi wire. Manufacturing companies claim that the addition of copper would allow the orthodontist to more easily engage larger archwires earlier in treatment to mal-aligned teeth because copper having a lower stress hysteresis ${ }^{(11,12)}$.

Orthodontic tooth movement has been defined as the result of a biologic response to interference in the physiologic equilibrium of the dento-facial complex by an externally applied force ${ }^{(13)}$.
As a fact, orthodontic treatment takes long time and to prevent this longevity of treatment several approaches have been studied. Some of them are mechanical, others surgical, also there is biological substances injection which applied buccally to the teeth, and finally there is the physical methods for acceleration. One of the recent physical methods of acceleration is the low level laser therapy (LLLT) application, which proved to be effective in alveolar bone remodeling and healing processes by increasing the number of both osteoclasts and osteoblasts, leading to movement acceleration during orthodontic treatment ${ }^{(14)}$.

Therefore, the present study was done to compare the clinical effect of low level laser therapy on two types of NiTi archwires (superelastic NiTi and Copper NiTi) in terms of effieciency in leveling and alignment and also to compare between (superelastic NiTi and Copper NiTi) archwires in terms of effieciency in leveling and alignment without laser and also to compare between (superelastic NiTi, Copper NiTi) archwires with laser and (superelastic NiTi, Copper NiTi) archwires without laser respectively in terms of effieciency in leveling and alignment.

\section{MATERIAL AND METHODS}

\section{Patient selection:}

A total of 32 patients with crowding in lower anterior teeth aged 16-21 years old were used in this study. These patients were selected from those attending at the orthodontic clinic, Faculty of Dental Medicine for Girls, Al Azhar University.

Inclusion criteria: All patients had no history of previous orthodontic treatment, absence of any anterior tooth that could be blocked out, and there was no need for extraction for any of lower anterior teeth in treatment plan.

\section{Operative procedure:}

After the separation phase, molar bands with tube of size $(0.022 \times 0.028)$ were selected for the right and left first molars. 
In all patients, the upper and lower arches were fitted by an orthodontic appliance constructed with brackets with $(0.022 \times 0.028)$ slot. Brackets were bonded with light cured composite by LED light curing unit.

\section{Patients grouping:}

Patients were divided into four groups ( 8 for each):

Group I: copper NiTi wire group with LLLT application (LC group).

Group II: superelastic NiTi wire group with LLLT application (LS group).

Group III: copper NiTi wire group without LLLT application (WLC group).

Group IV: superelastic NiTi wire group without LLLT application (WLS group).

\section{Wire placement:}

Leveling and alignment was done in group I and group III by 0.014 inch copper NiTi archwires. And in group II and group IV was done by 0.014 inch superelastic NiTi archwires.

Debonding was not allowed during treatment and specially during the initial stage of treatment. If any bracket was debonded the re-bonding was done during the first 24 hours, otherwise the case was considered to be a dropout and not included in the results.

\section{Laser application procedure:}

Immediately after inserting the archwire, a low level laser dose was applied for the laser group patients using a $635 \mathrm{~nm}$ wavelength device (Lasotronix Smart M pro diode laser, Poland) with a $2.5 \mathrm{~J} / \mathrm{cm}^{2}$ irradiation dose and $150 \mathrm{MW}$ output. The laser beam was delivered using tapered round 2 mm diameter tip.

Each root of the mandibular incises (all six roots) received a laser beam. The roots were divided by an imaginary horizontal line into cervical half and apical half. Each half received a laser beam directly to its center and perpendicular to the root surface.
This process was done for both sides buccal and lingual making four points of laser application two in each side of the root. The device tip was in direct contact with the oral mucosa from both sides buccal and lingual, to maximize benefit that could be taken from the beam.

The laser application was repeated with the same measurements and direction after the first application by 7,14 and 28 days.

\section{Cast measurements:}

An alginate impression was taken of the mandibular arch of the patient at four different times to calculate the outcomes. First impression before orthodontic treatment was referred to (T0), then after two weeks of laser application (T1), after four weeks of laser application (T2) and the final impression was taken after six weeks of laser application (T3).

Comparison was done between I and II groups, between III and IV groups, between I and III groups and between II and IV groups through orthodontic study cast and intraoral photographs before treatment (T0), after 2 weeks (T1), after 4 weeks (T2) and after 6 weeks (T3) of treatment.

\section{STATISTICAL ANALYSIS}

Statistical analysis was performed using a commercially available software program (SPSS Chicago, IL, USA).

Numerical data was described as mean and standard deviation or as median and range as appropriate according to the normality of the data. Data was compared using Kruskall Wallis or ANOVA test depending on normality.

The level of significance was set at $\mathrm{P}<0.05$. All tests were two tailed.

\section{RESULTS}

Statistically there was no significant difference found amongst group I and group II at different observation times. 
Statistically there was no significant difference found amongst group III and group IV at different observation times.

Statistically there was no significant difference found amongst group I and group III at different observation times.
Statistically there was no significant difference found amongst group II and group IV at different observation times.

Comparsion between different groups at different intervals: (Table 1) and (Fig. 1).

Table (1): Table showing Descriptive statistics of percent change in different intervals in different groups:

\begin{tabular}{|c|c|c|c|c|c|c|c|c|}
\hline & & & Std. & Std & $\begin{array}{l}95 \% \\
\text { Interv }\end{array}$ & $\begin{array}{l}\text { idence } \\
\text { Mean }\end{array}$ & & \\
\hline & & ivean & Dev & Error & $\begin{array}{l}\text { Lower } \\
\text { Bound }\end{array}$ & $\begin{array}{l}\text { Upper } \\
\text { Bound }\end{array}$ & 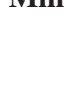 & $\ln 1 \mathrm{x}$ \\
\hline $\begin{array}{l}\text { First interval } \\
\quad \text { (T0-T1) }\end{array}$ & $\begin{array}{c}\text { LC } \\
\text { LS } \\
\text { WLC } \\
\text { WLS }\end{array}$ & $\begin{array}{l}3.45 \\
2.53 \\
2.96 \\
2.85\end{array}$ & $\begin{array}{l}2.58 \\
1.58 \\
1.22 \\
2.04\end{array}$ & $\begin{array}{l}.91 \\
.56 \\
.43 \\
.72\end{array}$ & $\begin{array}{l}1.30 \\
1.21 \\
1.94 \\
1.14\end{array}$ & $\begin{array}{l}5.60 \\
3.84 \\
3.98 \\
4.56\end{array}$ & $\begin{array}{l}.00 \\
.00 \\
.00 \\
.00\end{array}$ & $\begin{array}{l}6.90 \\
3.85 \\
3.85 \\
6.25\end{array}$ \\
\hline $\begin{array}{l}\text { Second interval } \\
\text { (T1-T2) }\end{array}$ & $\begin{array}{c}\text { LC } \\
\text { LS } \\
\text { WLC } \\
\text { WLS }\end{array}$ & $\begin{array}{l}3.81 \\
4.33 \\
4.10 \\
2.90\end{array}$ & $\begin{array}{l}2.38 \\
2.00 \\
2.36 \\
2.15\end{array}$ & $\begin{array}{l}.84 \\
.71 \\
.84 \\
.76\end{array}$ & $\begin{array}{l}1.82 \\
2.66 \\
2.12 \\
1.10\end{array}$ & $\begin{array}{l}5.80 \\
6.00 \\
6.07 \\
4.70\end{array}$ & $\begin{array}{c}.00 \\
3.03 \\
.00 \\
.00\end{array}$ & $\begin{array}{l}7.69 \\
7.69 \\
7.41 \\
6.67\end{array}$ \\
\hline $\begin{array}{l}\text { Third interval } \\
\text { (T2-T3) }\end{array}$ & $\begin{array}{c}\text { LC } \\
\text { LS } \\
\text { WLC } \\
\text { WLS }\end{array}$ & $\begin{array}{l}4.59 \\
4.26 \\
3.95 \\
2.75\end{array}$ & $\begin{array}{l}3.30 \\
3.73 \\
2.26 \\
2.56\end{array}$ & $\begin{array}{c}1.17 \\
1.32 \\
.80 \\
.91\end{array}$ & $\begin{array}{c}1.82 \\
1.14 \\
2.06 \\
.61\end{array}$ & $\begin{array}{l}7.35 \\
7.37 \\
5.84 \\
4.90\end{array}$ & $\begin{array}{l}.00 \\
.00 \\
.00 \\
.00\end{array}$ & $\begin{array}{c}10.71 \\
10.71 \\
6.67 \\
6.25\end{array}$ \\
\hline $\begin{array}{l}\text { Overall } \\
\text { (T0-T4) }\end{array}$ & $\begin{array}{c}\text { LC } \\
\text { LS } \\
\text { WLC } \\
\text { WLS }\end{array}$ & $\begin{array}{c}12.31 \\
11.52 \\
11.39 \\
8.71\end{array}$ & $\begin{array}{l}4.96 \\
5.05 \\
3.15 \\
2.75\end{array}$ & $\begin{array}{c}1.75 \\
1.79 \\
1.11 \\
.97\end{array}$ & $\begin{array}{l}8.16 \\
7.30 \\
8.76 \\
6.40\end{array}$ & $\begin{array}{l}16.45 \\
15.75 \\
14.02 \\
11.01\end{array}$ & $\begin{array}{l}3.13 \\
6.45 \\
6.67 \\
6.06\end{array}$ & $\begin{array}{l}19.23 \\
19.23 \\
16.13 \\
13.33\end{array}$ \\
\hline
\end{tabular}

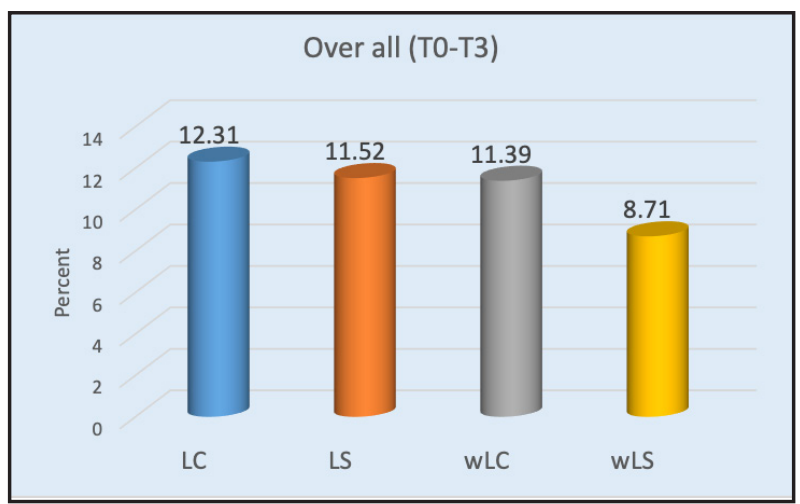

Figure (1) Bar chart illustrating mean overall percent change (T0-T3) in different groups.

\section{DISCUSSION}

The first stage of orthodontic treatment entails leveling and aligning. Initiation of orthodontic treatment with "leveling" archwires requires wires with great range to accommodate the usual malalignment of bracket slots in the untreated malocclusion ${ }^{\left(3 \_5\right)}$.

Two types of wires can be used in leveling and alignment: a multistranded stainless steel wire or a nitinol-type wire. The last one have three types: conventional, superelastic, and thermoactivated types of nickel titanium arch wires ${ }^{(10)}$. 
A study ${ }^{(15)}$ concluded that the copper nickel titanium is more effective than other types of nickel-titanium wires regarding the alleviation that could done to the crowding relief of the mandibular anterior teeth. While there are other converse studies $(16,17)$ which concluded that there is no significant difference among superelastic NiTi and CuNiTi wires in terms of alignment efficiency.

Several approaches have been used to increase the velocity of orthodontic tooth movement by enhancing the bone remodeling. Recently, low level laser therapy has been used as one of these methods (18). So, the motive to carry out the present study was compare clinically effect of low level laser therapy on two types of NiTi archwires (superelastic NiTi and Copper NiTi), compare between (superelastic NiTi, Copper NiTi) archwires with laser and (superelastic NiTi, Copper NiTi) archwires without laser respectively and compare between (superelastic NiTi and Copper NiTi) archwires without laser application in terms of effieciency of leveling and alignment of dental crowding cases.

In this study, the wavelength of the laser device was $635 \mathrm{~nm}$, which is in the range between 600$1000 \mathrm{~nm}$ (this was considered as the optimal range of application). It also had a low coefficient of absorption in water and chromophores (as hemoglobin), leading to proper laser penetration into the tissues. ${ }^{(19)}$ This was in agreement with previous study that was used the same wavelength of LLL found a positive effect regarding enhancement of the orthodontic treatment acceleration ${ }^{(19,20)}$.

The energy was adjusted to $2.5 \mathrm{~J} /$ point, which is considered as low irradiation dose. This dose was used before in previous study with an effective result on acceleration but contrary to another converse study, which also used low irradiation doses ${ }^{(14)}$.

Another study recommended that, for tooth movement acceleration the range from $0.2 \mathrm{~J}$ to $2.2 \mathrm{~J}$ for the energy of the laser beam, as this is the effective range clinically. Furthermore, previous studies with the same energy level found out a positive effect on acceleration of movement. Accordingly, $2.2 \mathrm{~J} /$ point was used in this study ${ }^{(14)}$.

All patients received 0.014-inch NiTi wires. Half of them received $\mathrm{Cu}$ NiTi wires and other half received superelastic NiTi wires. And this was in accordance with previous study ${ }^{(9)}$ which also ysed the same inch of this wires.

To assess the outcomes of the treatment by laser application the little's irregularity index (LII) was used because it is simple and reproducible method of measuring anterior arch-length discrepancy. This finding were in accordance with a previous study ${ }^{(9)}$ which also used LII method.

Regarding the rate of orthodontic tooth movement in group I (laser group with copper NiTi wire in which accelerated orthodontic tooth movement performed by low level laser therapy application on lower anterior teeth) and group III (copper NiTi wire group in which leveling and alignment was performed by copper NiTi wire without laser application). The current study approved that, statically no significant difference among both groups along the different intervals ( $\mathrm{P}$-value $=$ $0.638,0.815,0.660$ and 0.666$)$ respectively.

This result was in agreement with similar previous study ${ }^{(21)}$ which concluded that, with the parameters that have been used in the study, the low level laser therapy (LLLT) didn't affect movement of the tooth.

This finding was in disagreement with other study ${ }^{(22)}$ which concluded that LLLT does accelerate human teeth movement and this may be due to the difference in the parameter settings used as this study used $780 \mathrm{~nm}$ wave length while in the present study $635 \mathrm{~nm}$ wave length was used.

Regarding the rate of orthodontic tooth movement in group II (laser group with superelastic NiTi wire in which accelerated orthodontic tooth movement performed by low level laser therapy application on lower anterior teeth) and group IV (superelastic NiTi wire group in which leveling 
and alignment was performed by superelastic NiTi wire without laser application), The current study showed that there was no difference among the both groups of the study during variant intervals (P-value $=0.730,0.190,0.365$ and 0.194$)$ respectively.

This result was in accordance with previous study ${ }^{(23)}$ which found that there was no significant difference in terms of tooth movement between the irradiated and non-irradiated sides at any time point.

This finding was in contrast with recent study ${ }^{(14)}$ which found that LLLT is an effective method for accelerating orthodontic tooth movement and this may be due to the area of laser application as in this study laser was applied on maxilla while in present study laser was applied on mandible.

Regarding the rate of orthodontic tooth movement in group I (laser group with copper NiTi wire in which accelerated orthodontic tooth movement performed by low level laser therapy application on lower anterior teeth) (LC group) and group II (laser group with superelastic NiTi wire in which accelerated orthodontic tooth movement performed by low level laser therapy application on lower anterior teeth) (LS group), The current study showed that there is no significant difference between copper NiTi wire and superelastic NiTi wire with low level laser therapy application in leveling and alignment efficiency at the different intervals (P-value $=0.405,0.644,0.845$ and 0.759 ) respectively.

This result was in agreement with similar recent study ${ }^{(16)}$ evaluate the alignment efficiency of nickeltitanium and copper-nickel-titanium archwires but without laser application and concluded that the effects of NiTi and $\mathrm{Cu}$ NiTi round archwires were similar in terms of their alignment efficiency.

This finding was in disagreement with another similar study (15) which studied the mandibular anterior alleviation with both nickel titanium wire types, copper nickel titanium and nickel titanium, but without laser application and found that $\mathrm{Cu} \mathrm{NiTi}$ wires is better than nickel-titanium wires and this may be due to increase the time of this study than present study.

Regarding the rate of orthodontic tooth movement in group III (copper NiTi wire group in which leveling and alignment was performed by copper NiTi wire without laser application) (WLC group) and group IV (superelastic NiTi wire group in which leveling and alignment was performed by superelastic NiTi wire without laser application) (WLS group), The current study showed that there is no significant difference between copper NiTi wire and superelastic NiTi wire in leveling and alignment efficiency at the different intervals (P-value $=0.895$, $0.309,0.340$ and 0.092 ) respectively.

This result was in agreement with previous study (9) which concluded that the three forms of NiTi wires (superelastic nickel-titanium, thermoelastic NiTi and conventional NiTi) were typical in the efficiency of alignment at the initial stage of the treatment (aligning stage) by fixed orthodontic appliance.

This finding was in disagreement with another study ${ }^{(15)}$ which found that $\mathrm{Cu}$ NiTi wires is better than nickel-titanium wires and this may be due to increase the time of this study than present study or may be due to the difference in the size of wire used as in this study 0.016 inch wire was used while in present study 0.014 inch wire was used.

\section{CONCLUSION}

Low level laser therapy is not effective as a method of acceleration during orthodontic movement of the teeth during the initial aligning stage of orthodontic treatment either with superelastic NiTi wire or with $\mathrm{Cu}$ NiTi wire.

No significant differences regarding rate of orthodontic tooth movement during leveling and alignment were observed between 0.014 inch copper NiTi archwire and 0.014 inch superelastic $\mathrm{NiTi}$ archwire groups at the different intervals with and without laser application. 


\section{REFERENCES}

1. Baldridge DW. Leveling the curve of Spee: Its effect on mandibular arch lengths. J Clin Orthod. 1969; 3:26-41.

2. Spee FG. The gliding path of the mandible along the skull. J Am Dent Assoc. 1980; 100:670-5.

3. Hain M, Dhopatkar A, Rock P. The effect of ligation method on friction in sliding mechanics. Am J Orthod Dentofacial Orthop. 2003; 123:416-22.

4. Kazanji MN, Watkinson AC. Soft lining materials: Their absorption of, and solubility in, artificial saliva. Br Dent J. 1988; 165:91-4.

5. Andrews LF. The 6-elements orthodontic philosophy: Treatment goals, classification, and rules for treating. Am J Orthod Dentofacial Orthop. 2015; 148:883-7.

6. Zinelis S, Al Jabbari YS, Gaintantzopoulou M, Eliades G, Eliades T. Mechanical properties of orthodontic wires derived by instrumented indentation testing (IIT) according to ISO 14577. Prog Orthod. 2015; 16:9.

7. Jyothikiran H, Shantharaj R, Batra P, Subbiah P, Lakshmi B, Kudagi V. Total recall: An update on orthodontic wires. Int J Orthod. 2014; 25:47-56.

8. Lombordo L, Marafioti M, Steanoni F, Mollica F, Siciliani G. Load deflection characteristics of nickel titanium initial archwires. Angle Orthod. 2012; 82:507-21.

9. Abdelrahman SR, Al-Nimri SK, Al Maaitah FE. A clinical comparison of three aligning archwires in terms of alignment efficiency: A prospective clinical trial. Angle Orthod. 2015; 85:434-9.

10. Bishara SE, Winterbottom JM, Sulieman AH, Rim K, Jakobsen JR. Comparisons of the thermodynamic properties of three nickel-titanium orthodontic archwires. Angle Orthod. 1995; 65:117-22.

11. Gravina AM, Canavarro C, Elias NC, Chaves MAGM, Brunharo PVHI, Quintão ACC. Mechanical properties of NiTi and CuNiTi wires used in orthodontic treatment. Part 2: Microscopic surface appraisal and metallurgical characteristics. Dent press J Orthod. 2014; 19:69-76.

12. Gill FJ, Planell JA. Effect of copper addition on the superelastic behavior of $\mathrm{Ni}-\mathrm{Ti}$ shape memory alloys for orthodontic applications. J Biomed Res (Appl Biomater). 1999; 48:682-8.
13. Hashimoto F., Kobayashi Y., Mataki S., Kobayashi K., Kato Y., Sakai H. Administration of osteocalcin accelerates orthodontic tooth movement induced by a closed coil spring in rats. Eur J Ortho. 2001; 23:535-45.

14. Hassan MMA, Sultan K, Hamadah O. Low-level laser therapy effectiveness in accelerating orthodontic tooth movement: A randomized controlled clinical trial. Angle Orthod. 2017; 87:499-504.

15. Pandis N, Polychronopoulou A, Eliades T. Alleviation of mandibular anterior crowding with copper-nickel-titanium vs nickel-titanium wires: a double-blind randomized control trial. Am J Orthod Dentofacial Orthop. 2009; 136:152-7.

16. Aydın B, Şenışık NE, Koşkan Ö. Evaluation of the alignment efficiency of nickel-titanium and copper-nickel-titanium archwires in patients undergoing orthodontic treatment over a 12-week period: A single-center, randomized controlled clinical trial. Korean J Orthod. 2018; 48:153-62.

17. Ulhaq A, Esmail Z, Kamaruddin A, Meadows S, Daus J, Vitale M, Perillo L, Sherriff M, Bister D. Alignment efficiency and esthetic performance of 4 coated nickel-titanium archwires in orthodontic patients over 8 weeks: A multicenter randomized clinical trial. Am J Orthod Dentofacial Orthop. 2017; 152:744-52.

18. Parker S. Laser regulation and safety in general dental practice. Br Dent J. 2007; 202:523-32.

19. Yassaei S, Fekrazad R, Shahraki N. Effect of low level laser therapy on orthodontic tooth movement: a review article. jdt.tums.ac.ir. 2013; 10:3.

20. Shirazi M, Akhoundi ASM, Javadi E, Kamali A, Motahhari $\mathrm{P}$, Rashidpour M, Chiniforush N. The effects of diode laser $(660 \mathrm{~nm})$ on the rate of tooth movements: an animal study. Lasers Med Sci. 2013; 30:713-8.

21. Heravi F, Moradi A, Ahrari F. The Effect of Low Level Laser Therapy on the Rate of Tooth Movement and Pain Perception during Canine Retraction. OHDM. 2014; 13.

22. Cruz RD, Kohara KE, Ribeiro SM, Wetter UN. Effects of Low-Intensity Laser Therapy on the Orthodontic Movement Velocity of Human Teeth: A Preliminary Study. Lasers Surg. Med. 2004; 35:117-20.

23. Dalaie K, Hamedi R, Kharazifard JM, Mahdian M, Bayat M. Effect of Low-Level Laser Therapy on Orthodontic Tooth Movement: A Clinical Investigation. J Dent (Tehran). 2015; 12:249-56. 